\title{
HIV RESISTANCE TO RALTEGRAVIR
}

\author{
François Clavel
}

Inserm U941, Institut Universitaire d’Hématologie, Hôpital Saint-Louis, Paris, France

\begin{abstract}
Similar to all antiretroviral drugs, failure of raltegravirbased treatment regimens to fully supress HIV replication almost invariably results in emergence of HIV resistance to this new drug. HIV resistance to raltegravir is the consequence of mutations located close to the integrase active site, which can be divided into three main evolutionary pathways: the $\mathrm{N} 155 \mathrm{H}$, the $\mathrm{Q} 148 \mathrm{R} / \mathrm{H} / \mathrm{K}$ and the $\mathrm{Y} 143 \mathrm{R} / \mathrm{C}$ pathways. Each of these primary mutations can be accompanied by a variety of secondary mutations that both increase resistance and compensate for the variable loss of viral replicative capacity that is often associated with primary resistance mutations. One unique property of HIV resistance to raltegravir is that each of these different resistance pathways are mutually exclusive and appear to evolve separately on distinct viral genomes. Resistance is frequently initiated by viruses carrying mutations of the $\mathrm{N} 155 \mathrm{H}$ pathway, followed by emergence and further dominance of viral genomes carrying mutations of the Q148R/H/K or of the Y143R/C pathways, which express higher levels of resistance. Even if some natural integrase polymorphisms can be part of this evolution process, these polymorphisms do not affect HIV susceptibility in the absence of primary mutations. Therefore, all HIV-1 subtypes and groups, together with HIV-2, are naturally susceptible to raltegravir. Finally, because interaction of integrase strand transfer inhibitors with the HIV integrase active site is comparable from one compound to another, raltegravir-resistant viruses express significant cross resistance to most other compounds of this new class of antiretroviral drugs.
\end{abstract}

\section{Basic Principles of HIV Drug Resistance}

Viral resistance is an almost unavoidable consequence of the failure of antiretroviral drugs to fully suppress active HIV replication in treated patients. Two principal mechanisms explain this phenomenon. First, the large majority of HIV-producing cells in vivo are highly activated CD 4 T-cells with a remarkably short half-life $[7,24,41]$. In spite of the short lifespan of these infected cells, the amounts of plasma virus, hence the total number of infected cells in the body, is usually stable over time in the absence of treatment. This implies that there exists a steady state between the rapid clearance of infected cells and the infection of new target cells by the virus. In consequence, the continuous regeneration of the pool of infected cells requires that infectious cycles by the virus be constantly reinitiated. Second, because of the intrinsically error-prone nature of reverse transcription of RNA into DNA [43, 46], each HIV infectious cycle introduces at least one ran- dom error per viral genome. As persistent HIV infection requires that multiple cycles of virus replication be constantly repeated, the population of viruses found in a single infected individual is highly diverse and constantly fluctuating over time $[6,36]$. In this context, when the pharmacological pressure exerted by antiretroviral drugs is unable to fully suppress ongoing cycles of HIV replication, emergence of viral variants carrying mutations that reduce HIV susceptibility to these drugs is almost inevitable.

Resistance is the consequence of mutations that modify the interaction between antiretroviral drugs and their viral target. Resistance mutations have been identified in all viral proteins targeted by antiretroviral drugs such as RT, protease and the envelope glycoprotein. Even when the drug does not directly target the virus but is directed against a cellular protein that is required for viral replication (the CCR 5 or CXCR4 receptors, for example), mutations in the viral protein that interacts with the cellular target have been found to emerge under appropriate conditions [55]. In some instances, single mutations able to express high-level resistance : this is the case of reverse transcriptase mutations $\mathrm{M} 184 \mathrm{~V}$, which mediates HIV resistance to 3TC and FTC [3], or of several mutations mediating resistance to non-nucleoside RT inhibitors (NNRTI) $[2,45]$. These drugs are described as having a low genetic barrier to resistance. For other drugs, high-level resistance requires that multiple mutations accumulate over time, with no single mutation able to promote significant resistance : these drugs are said to have a high genetic barrier to resistance $[8,12,27,37,54]$. The best examples of such drugs are protease inhibitors, to which individual changes in the HIV protease express only minor changes in susceptibility and for which development of clinically relevant resistance levels requires gradual accumulation of multiple different mutations [8, 27, 37]. The historical efficacy of highly active antiretroviral therapy (HAART) in HIV-infected individuals is based both on its antiviral potency, which most often leads to complete suppression of active viral replication, and on its ability to raise a high genetic barrier to viral resistance.

In this context, raltegravir (RAL), the first integrase strand transfer inhibitor (INSTI) that has been approved for clinical use, does not fundamentally differ from other antiretroviral drugs. Virological sudies conducted in patients from clinical trials evaluating RAL efficacy in vivo have found that resistance to RAL can emerge rapidly following treatment failure, identified IN mutations able to mediate high-level resistance to RAL, and revealed that the genetic barrier of resistance to RAL is relatively low. 


\section{EMERgEnCE of RAL RESISTANCE IN TREATED PATIENTS}

The first observations of HIV resistance to RAL in vivo essentially came from the BENCHMRK-I and BENCHMRK-II clinical trials [51]. In these large phase 2 studies, patients having failed several previous HAART regimens and infected by viruses expressing resistance to multiple antiretroviral drugs were proposed a combination of RAL with an " optimized » background of other drugs, which, based on RT and PR genotype, were believed to retain significant antiviral activity against the patient's virus. In a large proportion of these patients $(>60 \%)$, the RAL-based regimen was able to stably reduce plasma viremia to undetectable levels, even in instances where the background regimen was not predicted to be fully active. Not surprisingly, however, in patients with viruses expressing lower susceptibility to the background regimen, full suppression of viral replication was more difficult to reach and viral variants expressing resistance to RAL were found [9]. The most frequently observed mutations were substitutions $\mathrm{N} 155 \mathrm{H}, \mathrm{Q} 148 \mathrm{R} / \mathrm{H} / \mathrm{K}$ and Y143R/C (Fig. 1). The same mutations were also seen in a small-scale study by Malet et al. [33], of patients exhibiting early failure of salvage therapy with a regimen that included RAL. In these and further studies [50], some of the viral genomes emerging under RAL pressure were found to have selected other mutations that were not present before RAL treatment, such as mutations L74M, E92Q, T97A, E138A/K, G140S/A, G163R or V151I (Table 1). Of note, however, several studies reported that at least during the first weeks of RAL failure, a significant proportion of patients harbored viral sequences that did not exhibit any change in their baseline IN sequences [9, 29]. The mechanisms explaining this lack of resistance mutations, and particularly the pharmacological parameters of RAL pressure, were not assessed in these instances.

Overall, it became soon clear that resistance to RAL can proceed along three principal mutational pathways, each characterized by the presence of either of the three major mutations N155H, Q148R/H/K or $\mathrm{Y} 143 \mathrm{R} / \mathrm{C}$ [9]. The $\mathrm{N} 155 \mathrm{H}$ pathway is frequently associated with secondary mutations L74M, E92Q, T97A, G136R or V151I. The Q148R/H/K pathway is usually associated with secondary mutations E138A/K or G140A/S. The third pathway, involving primary mutations Y143C or Y143R, also frequently includes sec-

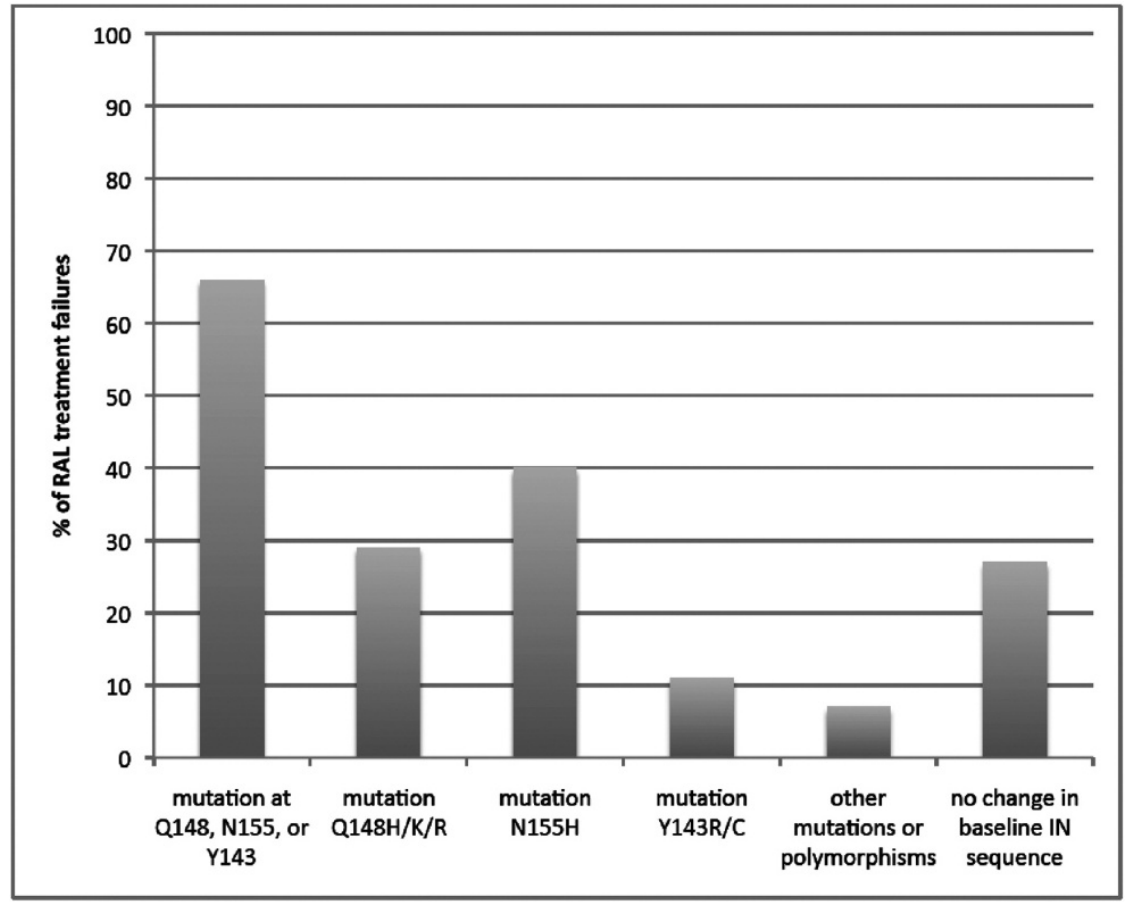

Fig. 1. Resistance genotypes in patients failing RAL-based salvage therapy in the BENCHMRK study (from Cooper et al., N Engl J Med 2008). The bars indicate the proportion of viruses carrying the indicated mutations within the population of patients exhibiting virological failure of raltegravir-based therapy.

Table 1. Amino-acid substitutions observed in viruses escaping RAL treatment (from Sichtig et al., J Antimicrob Ther 2009).

Primary (pathway-specific) mutations

Secondary mutations

Occasional mutations/polymorphisms
N155H, Q148R/H/K, Y143R/C

L74M, E92Q, T97A, Y143H, V151I, G163R, $\mathrm{E} 138 \mathrm{~A} / \mathrm{K}, \mathrm{G} 140 \mathrm{~S} / \mathrm{A}$

H51Y, T66I, V72I, L74A/I, S119R/G/P/T, T112I, F121Y, T125A/K, A128T, Q146K, S147G, S153Y/A, M154I, K156N, E157Q, K160D, V165I, V201I, I203M, T206S, S230R/N, V249I, R263K, C280Y 


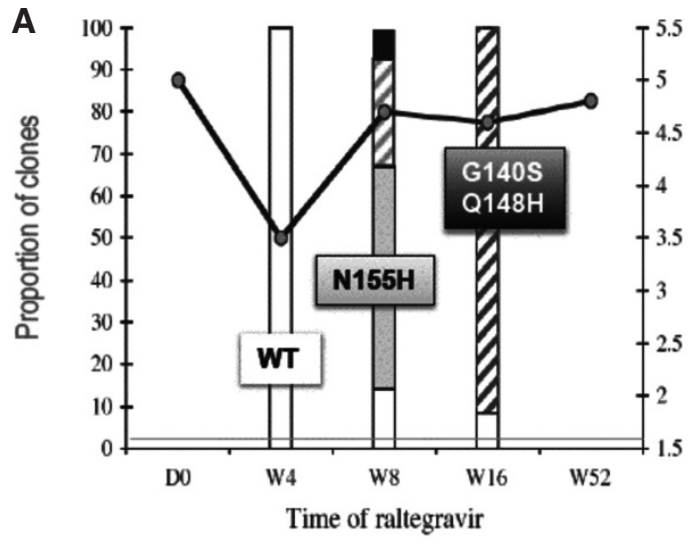

$\square$ WT $\square \mathrm{N} 155 \mathrm{H}$

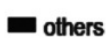

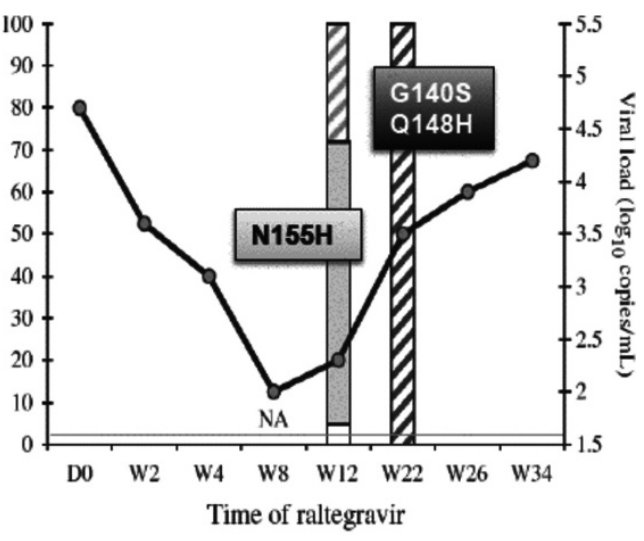

Q148R/H

G1403 + Q148R

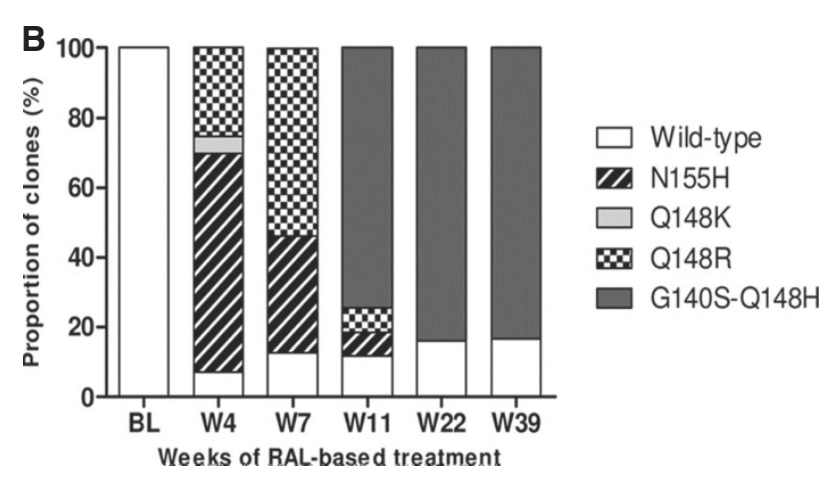

ondary mutations such as L74A/I, E92Q, T97A, I203M and/or S230R.

The aminoacid residues involved in primary resistance to RAL are highly conserved among all HIV subtypes [5] and are located close to the catalytic site of the enzyme. Interestingly, minimal overlap exists between the mutational pathways described as emerging during RAL failure and the IN mutations observed following in vitro selection for resistance to earlier generations of INSTI compounds. Indeed, while naphtyridine carboxylate derivatives were found to select for combinations of substitutions V72I, F121Y, T125K and V151I [22], diketo acid derivatives essentially led to emergence of mutation T66I in association with S153Y or M154I, or of substitution N155S [16, 23]. With these earlier compounds, the selected mutants appeared to express only low levels of resistance at the expense of marked losses in viral replicative capacity, which was consistent with the close proximity of some of the mutations with the key catalytic aminoacids of the integrase enzyme at positions D64, D116 and E152. It was therefore somewhat anticipated that mutations emerging under RAL pressure would also express limited resistance and significantly affect viral fitness, but this turned out not to be the case.

\section{The Unique Dynamics of RAL Resistance EVOLUTION IN VIVO}

Further insight into HIV resistance to RAL was obtained when investigators analysed the evolution of viral genotypes during the course of prolonged RAL failure. The first findings produced by these studies revealed that viral genotypes tend to change when HIV
Fig. 2. (A) clonal analysis of the evolution of HIV RAL resistance over time in two patients (from Malet et al., J Antimicrob Chemother 2009). The bars indicate the relative proportion of each mutational pathway within the population of viral clones sequenced. (B) clonal analysis of the evolution of RAL resistance over time in one patient (from Fransen et al., Antimicrob Agents Chemother 2009). The bars indicate the relative proportion of each mutational pathway within the population of viral clones sequenced.

continues to evolve under pharmacological pressure by RAL in vivo $[4,15,17,18,32,50]$. In particular, viruses carrying mutations of the $\mathrm{N} 155 \mathrm{H}$ pathway, whether $\mathrm{N} 155 \mathrm{H}$ alone or $\mathrm{N} 155 \mathrm{H}$ associated with one or more secondary mutations, appear to switch to genotypes expressing either mutations of the Q148R/H/K or of the Y143R/C pathways. Remarkably, analysis of individual clones from plasma HIV sequences revealed that the three mutional pathways leading to RAL resistance are in fact mutually exclusive $[17,18,32]$. None of the viral sequences examined in these studies revealed associations of mutation $\mathrm{N} 155 \mathrm{H}$ with mutations Q148R/H/K or $\mathrm{Y} 143 \mathrm{R} / \mathrm{C}$ on the same clones. As shown on figure 2 , viral sequences present in patient plasma after several weeks of viral escape under RAL pressure are a mixed population of viral genomes carrying mutations characteristic of either of the three main mutational pathways, with mutations of each pathway carried by distinct viral genomes. Thus, the apparent emergence of mutations belonging to the Q148R/H/K pathway or of the $\mathrm{Y} 143 \mathrm{R} / \mathrm{C}$ pathways in the context of preexisting mutations of the $\mathrm{N} 155 \mathrm{H}$ pathway reflects the replacement of viruses carrying mutations of the $\mathrm{N} 155 \mathrm{H}$ pathway by viruses carrying mutations belonging to either of the two other pathways. According to this unique pattern of RAL resistance evolution, it appears that mutations of the $\mathrm{N} 155 \mathrm{H}$ pathway, and particularly mutation N155H itself, may be the easiest way for HIV to acquire resistance to RAL early in the course of viral escape, but that further replication under RAL pressure almost always leads to dominance of viral genomres carrying mutations of the two other pathways. In the early weeks of RAL failure, when $\mathrm{N} 155 \mathrm{H}$ genomes consti- 

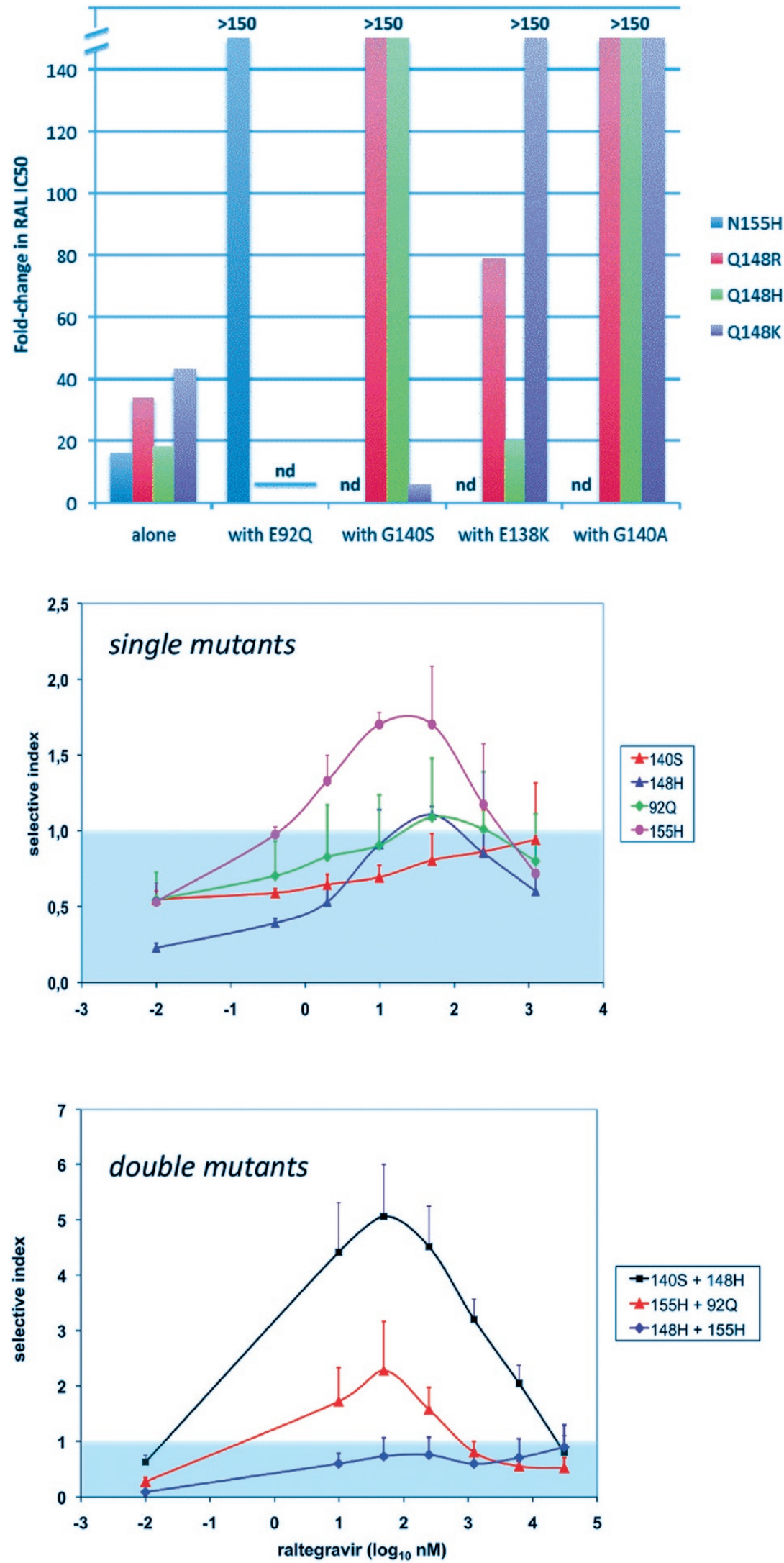

tute the dominant resistant species in the viral population, viral genomes expressing different substitutions at position 148 can coexist as minority species that compete against each other. As illustrated on figure $2 \mathrm{~A}$, these genomes can only become dominant once they have acquired an appropriate secondary mutation
Fig. 3. Phenotypic effect of secondary mutations on viruses carrying primary RAL resistance mutations (from Fransen et al., J Virol 2009). nd : not done.

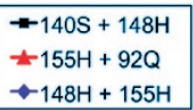

140S. Several observations, however, suggest that $\mathrm{N} 155 \mathrm{H}$ may not be the only mutation to initiate RAL resistance evolution. Cases of "secondary" mutations L74M and/or E92Q emerging first have been described. In other instances, mutations of the Q148R/H/K or of the $\mathrm{Y} 143 \mathrm{R} / \mathrm{C}$ pathways are ob- 
served at a very early stage with no trace of $\mathrm{N} 155 \mathrm{H}$ having been selected beforehand, suggesting that in these viruses, Q148R/H/K or Y143R/C could constitute a preferable early pathway for initial viral breach during RAL treatment.

\section{Phenotypic Properties of RAL Resistance Mutations}

The dynamics of HIV evolution under pharmacological pressure by RAL in vivo are largely explained by the phenotypic properties of the different IN mutants involved in this evolution, both in terms of resistance (fold-change in IC50) and in terms of replicative capacity (RC). Most studies have focused on the effect of primary and secondary mutations of the $\mathrm{N} 155 \mathrm{H}$ and Q148R/H/K pathways, leaving aside the Y143R/C pathway, for which little information is available. Phenotypic analysis of viral clones carrying the $\mathrm{N} 155 \mathrm{H}$ mutation have found that it mediated significant but moderate levels of resistance to RAL. Introduction of $\mathrm{N} 155 \mathrm{H}$ in a wild-type HIV-1 subtype B reference molecular clone such as HIV-1 IIIB or pNL4-3 produced a change in RAL IC50 of 16- to 32-fold, at the expense of minimal (30\%-40\%) loss of replicative capacity. Mutations at codon 148 appeared to produce stronger changes in RAL IC50 (18- to 78-fold, depending on the substitution and on the experimental system), together with a more prominent loss $(40 \%-70 \%)$ of RC. Thus, $\mathrm{N} 155 \mathrm{H}$ produces less resistance than $\mathrm{Q} 148 \mathrm{R} / \mathrm{H} / \mathrm{K}$, but had a milder impact on viral RC. When examined using the "selective advantage profile" system, which incorporates drug susceptibility and RC in a single assay expressing the selective advantage of a mutant virus relative to wild-type as a function of drug concentration $[34,42,44], \mathrm{N} 155 \mathrm{H}$ had clearly a strong positive advantage over a wide range of RAL concentration, as opposed to Q148H [44], which only expressed minimal selective advantage over wild-type across a markedly narrower range of RAL concentration (Fig. 4). Addition of secondary mutations both to $\mathrm{N} 155 \mathrm{H}$ and to Q148R/H/K mutations dramatically increased RAL resistance and significantly improved RC $[10,17,40,44]$. The association of either of the Q148 mutations with secondary G140S, G140A or E138K could produce fold-changes in IC50 that were above the maximal 150-fold resistance rate measurable in the Monogram assay in Fransen et al. [17], but this effect was only seen with specific pairs of Q148 and G140 substitutions. For example, secondary mutation G140S was found to exert maximal effect only when associated with Q148H or Q148R, but its association with Q148K reduced resistance from a 48-fold change in IC50 to a 6 fold-change, an effect that appears to be independent of viral RC [17]. Consistent with these findings, Quercia et al. reported that G140S produced a change in RAL IC50 of 1436-fold [44]. The addition of secondary mutation E92Q also markedly increased the level of resistance conferred by mutation $\mathrm{N} 155 \mathrm{H}$ with E92Q : viruses with both mutations expressed changes in RAL IC50 of $>150$-fold in Fransen et al. and of 492-fold in Quercia et al [17, 44]. When analysed using the selective advantage profile method, the combination of Q148H and G140S was found to express a level of advantage that was higher and wider than any of the other dual mutations tested. In addition to their effect on resistance, the association of
G140 mutations with Q148R/H/K mutations also helps improving viral RC. For example, in Fransen et al., addition of G140S to Q148H increased RC from $43 \%$ of wild type to $99 \%$. Similar findings were reported by Quercia et al. and Delelis et al [10,44]. Taken together, these findings reveal that as predicted, $\mathrm{N} 155 \mathrm{H}$ appears to be one of the less costly and most efficient solutions for RAL resistance when present on the HIV genome as a single mutation, explaining its frequent predominance in viral populations harvested early in the course of viral resistance evolution. While this mutation dominates, however, viral populations carrying other primary mutations of the Q148R/H/K or of the $\mathrm{Y} 143 \mathrm{R} / \mathrm{C}$ pathways are selected but cannot dominate as long as they only carry single mutations. When these viruses acquire secondary mutations such as G140A/S or $\mathrm{E} 138 \mathrm{~A} / \mathrm{K}$, however, the resulting gain in resistance, together with the improvement in viral RC allows rapid expansion and further dominance of these pathways over the initial $\mathrm{N} 155 \mathrm{H}$ mutants. The rapidity of these population changes may be dependent on the extent that $\mathrm{N} 155 \mathrm{H}$ mutants, alone or in combination with secondary mutations can suffice to promote pharmacologically relevant levels of resistance. Indeed, the IC50 fold-changes observed in primary viruses expressing the $\mathrm{N} 155 \mathrm{H}$ mutation alone appear to vary significantly from one viral strain to another [17], strongly suggesting that this mutation may exert different levels of resistance to RAL according of the viral genetic background. This parameter, together with the concentration of raltegravir found at the site of resistant virus selection, which may significantly vary from one patient to another, could also exert a strong effect on the kinetics of genetic switch from the $\mathrm{N} 155 \mathrm{H}$ pathway to the Q148R/H/K pathway in vivo.

\section{Molecular Mechanisms of RAL Resistance}

The strand-transfer reaction that leads to HIV DNA integration into host cellular DNA is catalysed by a dynamic complex associating an IN tetramer and the two ends of the linear viral DNA molecule $[1,13,14,19$, $25,30,38]$. Studies conducted using INSTIs have found that the binding site for this family of drugs is constituted both by elements of the enzyme itself and by elements of viral DNA. More specifically, these studies have pointed to the important role of a mobile loop structure that is located next to the D64-D116E152 catalytic triad and that is critical for the conformation of the IN active site. This loop structure is important both for binding of the ends of viral DNA to the IN tetramer and for catalytic activity. Once viral DNA is bound to the enzyme, the loop, together with the recessed 3' end and the 5' overhang of the processed viral DNA molecule, will undergo a change in conformation and participate in the creation of a hydrophobic pocket able to bind INSTIs. Some of the most important RAL resistance mutations, such as Q148R/H/K, Y143R/C and G140A/S, are located within this active site loop, which extends from residues 139 to 149 . In particular, residues Q148 and Y143 have been described as directly involved in the interaction of IN with viral DNA. Residue N155, which is involved in early RAL resistance in vivo, is located within a more structured region of the catalytic core domain, between the active site and two residues also known to bind viral DNA at positions 156 and 
159. Overall, current models propose that RAL resistance mutations affect binding of RAL to the IN catalytic domain both through changes that directly modify points of contact between the drug and the enzyme and through changes that modify DNA binding to IN. Similar to current models proposed for HIV resistance to protease inhibitors, one can predict that secondary mutations will create subtle structural readjustments able to compensate for the functional imbalance created by structural changes imparted to the IN-DNA complex by primary mutations, and by the same process able to reinforce the effect of these mutations on inhibitor binding and potency.

\section{HIV DIVERSITY AND RAL SUSCEPTIBILITY}

In spite of being one of the most conserved HIV proteins, significant variation of the IN aminoacid sequence can be seen within and between the different HIV-1 subtypes [5, 31, 39]. Some of the natural IN polymorphisms observed between HIV-1 strains have also been found to emerge in the course of resistance to RAL, a situation that is reminiscent of what is seen with protease inhibitors. In particular, polymorphims V72I, V74M/I, T97A, M154I, V165I and T206S are found with a frequency greater than $12 \%$ in some HIV1 subtypes [39]. Key resistance mutations $\mathrm{N} 155 \mathrm{H}$, Q148R/H/K and Y143R/C, however, are extremely rare in the absence of pharmacological pressure by RAL. Consequently, all RAL-naïve viral isolates tested so far retain near wild-type RAL susceptibility [53]. Similarly, HIV-1 group O and HIV-2 are naturally susceptible to RAL in vivo $[11,47,56]$. In HIV-2, recent data have shown that similar to HIV-1, resistance to RAL following in vivo viral escape is accompanied by early selection of viral genomes carrying mutation $\mathrm{N} 155 \mathrm{H}$, which in one instance was later replaced by a genotype expressing mutation Y143C $[47,56]$.

\section{CROSS-RESISTANCE}

All currently developed INSTIs interact with the catalytic core domain of IN and block HIV DNA integration into host cell DNA through a similar mechanism that relies upon comparable diketo-derived key pharmacophores $[35,48]$. Therefore, significant cross resistance is expected between the different INSTIs, an expectation that has been confirmed by most studies confronting this question. Following RAL, the most clinically advanced INSTI molecule is elvitegravir (EVG, formerly GS-9137), which is now in phase 3 development. Unlike RAL, EVG is metabolized by cytochrome P450 and can benenefit of pharmacological boosting by ritonavir or other P450 antagonists, thereby allowing for a single daily dosing. Early studies on EVG resistance $[21,28,49]$ have found that this drug was able to select for mutations E92Q, T66I and E138K, which have already been found in viruses escaping RAL, and for substitutions affecting aminoacids 146 and 147, next to key RAL resistance aminoacid Q148. Further selection experiments confirmed the central role of mutation E92Q and the frequent occurrence of E138E/K, Q148R, L74M and S230R in EVG resistance. These findings thus predicted significant cross-resistance between EVG and RAL. Phenotypic testing of viruses carrying various combinations of RAL resistance mutations including T66I, L74M,
E92Q, E138K, G140S, G148R/H/K and N155H confirmed extensive cross-resistance between RAL and EVG, in particular for viruses expressing combinations of mutations G140S and Q148R/H/K, which represent the majority of viruses having evolved under prolonged selective pressure by RAL [21, 26]. Similar cross-resistance was also found between RAL and GS9160, a novel compound at early stages of development by Gilead Sciences [26]. Two INSTIs have been recently developed jointly by Shionogi and GSK : S/GSK-364735 and S/GSK-1439572. While extensive cross-resistance between RAL and S/GSK-364735 has been described [20], cross-resistance between RAL and S/GSK-1439572 appears more limited [52]. In vitro selection using this drug leads to emergence of sustitution T124A, a common IN polymorphism that does not affect INSTI susceptibility, and of mutation S153F, at a position already found to mutate under pressure by diketo acid derivatives. In vitro susceptibility of common RAL resitant mutants to S/GSK-1439572 reveals that only combination of mutations G140S and Q148R/H reaches fold-changes in S/GSK-1439572 susceptibility above 10-fold, as compared with several hundred-fold for RAL. In spite of these encouraging results, further testing of primary viruses having accumulated multiple primary and secondary mutations and reached high-level resistance under RAL pressure is required before ensuring S/GSK-1439572 as a secondline INSTI drug with significant antiviral activity in patients having failed RAL-based treatment.

\section{REFERENCES}

1. Alian, A., S. L. Griner, V. Chiang, M. Tsiang, G. Jones, G. Birkus, R. Geleziunas, A. D. Leavitt, and R. M. Stroud. 2009. Catalytically-active complex of HIV-1 integrase with a viral DNA substrate binds anti-integrase drugs. Proc Natl Acad Sci U S A 106:8192-7.

2. Bacheler, L. T., E. D. Anton, P. Kudish, D. Baker, J. Bunville, K. Krakowski, L. Bolling, M. Aujay, X. V. Wang, D. Ellis, M. F. Becker, A. L. Lasut, H. J. George, D. R. Spalding, G. Hollis, and K. Abremski. 2000. Human immunodeficiency virus type 1 mutations selected in patients failing efavirenz combination therapy. Antimicrob Agents Chemother 44:2475-84.

3. Boucher, C. A., N. Cammack, P. Schipper, R. Schuurman, P. Rouse, M. A. Wainberg, and J. M. Cameron. 1993. High-level resistance to (-) enantiomeric 2'-deoxy-3'-thiacytidine in vitro is due to one amino acid substitution in the catalytic site of human immunodeficiency virus type 1 reverse transcriptase. Antimicrob Agents Chemother 37:2231-4.

4. Canducci, F., M. Sampaolo, M. C. Marinozzi, E. Boeri, V. Spagnuolo, A. Galli, A. Castagna, A. Lazzarin, M. Clementi, and N. Gianotti. 2009. Dynamic patterns of human immunodeficiency virus type 1 integrase gene evolution in patients failing raltegravir-based salvage therapies. AIDS 23:455-60

5. Ceccherini-Silberstein, F., I. Malet, R. D'Arrigo, A. Antinori, A. G. Marcelin, and C. F. Perno. 2009. Characterization and structural analysis of HIV-1 integrase conservation. AIDS Rev 11:17-29.

6. Charpentier, C., D. E. Dwyer, F. Mammano, D. Lecossier, F. Clavel, and A. J. Hance. 2004. Role of minority populations of human immunodeficiency virus type 1 in the evolution of viral resistance to protease inhibitors. J Virol 78:4234-47. 
7. Coffin, J. M. 1995. HIV population dynamics in vivo: implications for genetic variation, pathogenesis, and therapy. Science 267:483-9.

8. Condra, J. H., W. A. Schleif, O. M. Blahy, L. J. Gabryelski, D. J. Graham, J. C. Quintero, A. Rhodes, H. L. Robbins, E. Roth, M. Shivaprakash, and et al. 1995. In vivo emergence of HIV-1 variants resistant to multiple protease inhibitors. Nature 374:569-71.

9. Cooper, D. A., R. T. Steigbigel, J. M. Gatell, J. K. Rockstroh, C. Katlama, P. Yeni, A. Lazzarin, B. Clotet, P. N. Kumar, J. E. Eron, M. Schechter, M. Markowitz, M. R. Loutfy, J. L. Lennox, J. Zhao, J. Chen, D. M. Ryan, R. R. Rhodes, J. A. Killar, L. R. Gilde, K. M. Strohmaier, A. R. Meibohm, M. D. Miller, D. J. Hazuda, M. L. Nessly, M. J. DiNubile, R. D. Isaacs, H. Teppler, and B. Y. Nguyen. 2008. Subgroup and resistance analyses of raltegravir for resistant HIV-1 infection. N Engl J Med 359:355-65.

10. Delelis, O., I. Malet, L. Na, L. Tchertanov, V. Calvez, A. G. Marcelin, F. Subra, E. Deprez, and J. F. Mouscadet. 2009. The G140S mutation in HIV integrases from raltegravir-resistant patients rescues catalytic defect due to the resistance Q148H mutation. Nucleic Acids Res 37:1193201.

11. Depatureaux, A., M. Leoz, G. Le Moal, J. Pathé, J. Pavie, F. Simon, and J. Plantier. 2009. Raltegravir is effective in HIV-1 group O infected patients. 5th IAS Conference on HIV Pathogenesis, Treatment and Prevention:Cape Town, South Africa, July 2009.

12. Dierynck, I., M. De Wit, E. Gustin, I. Keuleers, J. Vandersmissen, S. Hallenberger, and K. Hertogs. 2007. Binding kinetics of darunavir to human immunodeficiency virus type 1 protease explain the potent antiviral activity and high genetic barrier. J Virol 81:13845-51.

13. Dolan, J., A. Chen, I. T. Weber, R. W. Harrison, and J. Leis. 2009. Defining the DNA substrate binding sites on HIV-1 integrase. J Mol Biol 385:568-79.

14. Esposito, D., and R. Craigie. 1998. Sequence specificity of viral end DNA binding by HIV-1 integrase reveals critical regions for protein-DNA interaction. EMBO J 17:583243.

15. Ferns, R. B., S. Kirk, J. Bennett, I. Williams, S. Edwards, and D. Pillay. 2009. The dynamics of appearance and disappearance of HIV-1 integrase mutations during and after withdrawal of raltegravir therapy. AIDS 23:2159-64.

16. Fikkert, V., B. Van Maele, J. Vercammen, A. Hantson, B. Van Remoortel, M. Michiels, C. Gurnari, C. Pannecouque, M. De Maeyer, Y. Engelborghs, E. De Clercq, Z. Debyser, and M. Witvrouw. 2003. Development of resistance against diketo derivatives of human immunodeficiency virus type 1 by progressive accumulation of integrase mutations. J Virol 77:11459-70.

17. Fransen, S., S. Gupta, R. Danovich, D. Hazuda, M. Miller, M. Witmer, C. J. Petropoulos, and W. Huang. 2009. Loss of raltegravir susceptibility by human immunodeficiency virus type 1 is conferred via multiple nonoverlapping genetic pathways. J Virol 83:11440-6.

18. Fransen, S., M. Karmochkine, W. Huang, L. Weiss, C. J. Petropoulos, and C. Charpentier. 2009. Longitudinal analysis of raltegravir susceptibility and integrase replication capacity of human immunodeficiency virus type 1 during virologic failure. Antimicrob Agents Chemother 53:4522-4.

19. Gao, K., S. L. Butler, and F. Bushman. 2001. Human immunodeficiency virus type 1 integrase: arrangement of protein domains in active cDNA complexes. EMBO J 20:3565-76.

20. Garvey, E. P., B. A. Johns, M. J. Gartland, S. A. Foster, W. H. Miller, R. G. Ferris, R. J. Hazen, M. R. Underwood, E. E. Boros, J. B. Thompson, J. G. Weatherhead, C. S. Koble, S. H. Allen, L. T. Schaller, R. G. Sherrill, T. Yoshinaga, M. Kobayashi, C. Wakasa-Morimoto, S. Miki,
K. Nakahara, T. Noshi, A. Sato, and T. Fujiwara. 2008. The naphthyridinone GSK364735 is a novel, potent human immunodeficiency virus type 1 integrase inhibitor and antiretroviral. Antimicrob Agents Chemother 52:9018.

21. Goethals, O., R. Clayton, M. Van Ginderen, I. Vereycken, E. Wagemans, P. Geluykens, K. Dockx, R. Strijbos, V. Smits, A. Vos, G. Meersseman, D. Jochmans, K. Vermeire, D. Schols, S. Hallenberger, and K. Hertogs. 2008. Resistance mutations in human immunodeficiency virus type 1 integrase selected with elvitegravir confer reduced susceptibility to a wide range of integrase inhibitors. J Virol 82:10366-74.

22. Hazuda, D. J., N. J. Anthony, R. P. Gomez, S. M. Jolly, J. S. Wai, L. Zhuang, T. E. Fisher, M. Embrey, J. P. Guare, Jr., M. S. Egbertson, J. P. Vacca, J. R. Huff, P. J. Felock, M. V. Witmer, K. A. Stillmock, R. Danovich, J. Grobler, M. D. Miller, A. S. Espeseth, L. Jin, I. W. Chen, J. H. Lin, K. Kassahun, J. D. Ellis, B. K. Wong, W. Xu, P. G. Pearson, W. A. Schleif, R. Cortese, E. Emini, V. Summa, M. K. Holloway, and S. D. Young. 2004. A naphthyridine carboxamide provides evidence for discordant resistance between mechanistically identical inhibitors of HIV-1 integrase. Proc Natl Acad Sci U S A 101:11233-8.

23. Hazuda, D. J., P. Felock, M. Witmer, A. Wolfe, K. Stillmock, J. A. Grobler, A. Espeseth, L. Gabryelski, W. Schleif, C. Blau, and M. D. Miller. 2000. Inhibitors of strand transfer that prevent integration and inhibit HIV-1 replication in cells. Science 287:646-50.

24. Ho, D. D., A. U. Neumann, A. S. Perelson, W. Chen, J. M. Leonard, and M. Markowitz. 1995. Rapid turnover of plasma virions and CD4 lymphocytes in HIV-1 infection. Nature 373:123-6.

25. Jenkins, T. M., D. Esposito, A. Engelman, and R. Craigie. 1997. Critical contacts between HIV-1 integrase and viral DNA identified by structure-based analysis and photocrosslinking. EMBO J 16:6849-59.

26. Jones, G. S., F. Yu, A. Zeynalzadegan, J. Hesselgesser, X. Chen, J. Chen, H. Jin, C. U. Kim, M. Wright, R. Geleziunas, and M. Tsiang. 2009. Preclinical evaluation of GS 9160, a novel inhibitor of human immunodeficiency virus type 1 integrase. Antimicrob Agents Chemother 53:1194203.

27. Kaplan, A. H., S. F. Michael, R. S. Wehbie, M. F. Knigge, D. A. Paul, L. Everitt, D. J. Kempf, D. W. Norbeck, J. W. Erickson, and R. Swanstrom. 1994. Selection of multiple human immunodeficiency virus type 1 variants that encode viral proteases with decreased sensitivity to an inhibitor of the viral protease. Proc Natl Acad Sci U S A 91:5597-601.

28. Kobayashi, M., K. Nakahara, T. Seki, S. Miki, S. Kawauchi, A. Suyama, C. Wakasa-Morimoto, M. Kodama, T. Endoh, E. Oosugi, Y. Matsushita, H. Murai, T. Fujishita, T. Yoshinaga, E. Garvey, S. Foster, M. Underwood, B. Johns, A. Sato, and T. Fujiwara. 2008. Selection of diverse and clinically relevant integrase inhibitor-resistant human immunodeficiency virus type 1 mutants. Antiviral Res 80:213-22.

29. Lennox, J. L., E. DeJesus, A. Lazzarin, R. B. Pollard, J. V. Madruga, D. S. Berger, J. Zhao, X. Xu, A. Williams-Diaz, A. J. Rodgers, R. J. Barnard, M. D. Miller, M. J. DiNubile, B. Y. Nguyen, R. Leavitt, and P. Sklar. 2009. Safety and efficacy of raltegravir-based versus efavirenz-based combination therapy in treatment-naive patients with HIV-1 infection: a multicentre, double-blind randomised controlled trial. Lancet 374:796-806.

30. Loizidou, E. Z., I. Kousiappa, C. D. Zeinalipour-Yazdi, D. A. Van de Vijver, and L. G. Kostrikis. 2009. Implications of HIV-1 M group polymorphisms on integrase inhibitor efficacy and resistance: genetic and structural in silico analyses. Biochemistry 48:4-6. 
31. Low, A., N. Prada, M. Topper, F. Vaida, D. Castor, H. Mohri, D. Hazuda, M. Muesing, and M. Markowitz. 2009. Natural polymorphisms of human immunodeficiency virus type 1 integrase and inherent susceptibilities to a panel of integrase inhibitors. Antimicrob Agents Chemother 53:4275-82.

32. Malet, I., O. Delelis, C. Soulie, M. Wirden, L. Tchertanov, P. Mottaz, G. Peytavin, C. Katlama, J. F. Mouscadet, V. Calvez, and A. G. Marcelin. 2009. Quasispecies variant dynamics during emergence of resistance to raltegravir in HIV-1-infected patients. J Antimicrob Chemother 63:795-804.

33. Malet, I., O. Delelis, M. A. Valantin, B. Montes, C. Soulie, M. Wirden, L. Tchertanov, G. Peytavin, J. Reynes, J. F. Mouscadet, C. Katlama, V. Calvez, and A. G. Marcelin. 2008. Mutations associated with failure of raltegravir treatment affect integrase sensitivity to the inhibitor in vitro. Antimicrob Agents Chemother 52:1351-8.

34. Mammano, F., V. Trouplin, V. Zennou, and F. Clavel. 2000. Retracing the evolutionary pathways of human immunodeficiency virus type 1 resistance to protease inhibitors: virus fitness in the absence and in the presence of drug. J Virol 74:8524-31.

35. Menendez-Arias, L. 2009. Molecular basis of human immunodeficiency virus drug resistance: An update. Antiviral Res.

36. Meyerhans, A., R. Cheynier, J. Albert, M. Seth, S. Kwok, J. Sninsky, L. Morfeldt-Manson, B. Asjo, and S. WainHobson. 1989. Temporal fluctuations in HIV quasispecies in vivo are not reflected by sequential HIV isolations. Cell 58:901-10.

37. Molla, A., M. Korneyeva, Q. Gao, S. Vasavanonda, P. J. Schipper, H. M. Mo, M. Markowitz, T. Chernyavskiy, P. Niu, N. Lyons, A. Hsu, G. R. Granneman, D. D. Ho, C. A. Boucher, J. M. Leonard, D. W. Norbeck, and D. J. Kempf. 1996. Ordered accumulation of mutations in HIV protease confers resistance to ritonavir. Nat Med 2:760-6.

38. Mouscadet, J. F., R. Arora, J. Andre, J. C. Lambry, O. Delelis, I. Malet, A. G. Marcelin, V. Calvez, and L. Tchertanov. 2009. HIV-1 IN alternative molecular recognition of DNA induced by raltegravir resistance mutations. J Mol Recognit 22:480-94.

39. Myers, R. E., and D. Pillay. 2008. Analysis of natural sequence variation and covariation in human immunodeficiency virus type 1 integrase. J Virol 82:9228-35.

40. Nakahara, K., C. Wakasa-Morimoto, M. Kobayashi, S. Miki, T. Noshi, T. Seki, M. Kanamori-Koyama, S. Kawauchi, A. Suyama, T. Fujishita, T. Yoshinaga, E. P. Garvey, B. A. Johns, S. A. Foster, M. R. Underwood, A. Sato, and T. Fujiwara. 2009. Secondary mutations in viruses resistant to HIV-1 integrase inhibitors that restore viral infectivity and replication kinetics. Antiviral Res 81:141-6.

41. Perelson, A. S., A. U. Neumann, M. Markowitz, J. M. Leonard, and D. D. Ho. 1996. HIV-1 dynamics in vivo: virion clearance rate, infected cell life-span, and viral generation time. Science 271:1582-6.

42. Perrin, V., and F. Mammano. 2003. Parameters driving the selection of nelfinavir-resistant human immunodeficiency virus type 1 variants. J Virol 77:10172-5.

43. Preston, B. D., B. J. Poiesz, and L. A. Loeb. 1988. Fidelity of HIV-1 reverse transcriptase. Science 242:1168-71.

44. Quercia, R., E. Dam, D. Perez-Bercoff, and F. Clavel. 2009. Selective-advantage profile of human immunodeficiency virus type 1 integrase mutants explains in vivo evolution of raltegravir resistance genotypes. J Virol 83:10245-9.

45. Richman, D. D., D. Havlir, J. Corbeil, D. Looney, C. Ignacio, S. A. Spector, J. Sullivan, S. Cheeseman, K. Bar- ringer, D. Pauletti, and et al. 1994. Nevirapine resistance mutations of human immunodeficiency virus type 1 selected during therapy. J Virol 68:1660-6.

46. Roberts, J. D., K. Bebenek, and T. A. Kunkel. 1988. The accuracy of reverse transcriptase from HIV-1. Science 242:1171-3

47. Salgado, M., C. Toro, A. Simon, C. Garrido, F. Blanco, V. Soriano, and B. Rodes. 2009. Mutation N155H in HIV-2 integrase confers high phenotypic resistance to raltegravir and impairs replication capacity. J Clin Virol 46:173-5.

48. Serrao, E., S. Odde, K. Ramkumar, and N. Neamati. 2009. Raltegravir, elvitegravir, and metoogravir: the birth of "me-too" HIV-1 integrase inhibitors. Retrovirology 6:25.

49. Shimura, K., E. Kodama, Y. Sakagami, Y. Matsuzaki, W. Watanabe, K. Yamataka, Y. Watanabe, Y. Ohata, S. Doi, M. Sato, M. Kano, S. Ikeda, and M. Matsuoka. 2008. Broad antiretroviral activity and resistance profile of the novel human immunodeficiency virus integrase inhibitor elvitegravir (JTK-303/GS-9137). J Virol 82:764-74.

50. Sichtig, N., S. Sierra, R. Kaiser, M. Daumer, S. Reuter, E. Schulter, A. Altmann, G. Fatkenheuer, U. Dittmer, H. Pfister, and S. Esser. 2009. Evolution of raltegravir resistance during therapy. J Antimicrob Chemother 64:25-32.

51. Steigbigel, R. T., D. A. Cooper, P. N. Kumar, J. E. Eron, M. Schechter, M. Markowitz, M. R. Loutfy, J. L. Lennox, J. M. Gatell, J. K. Rockstroh, C. Katlama, P. Yeni, A. Lazzarin, B. Clotet, J. Zhao, J. Chen, D. M. Ryan, R. R. Rhodes, J. A. Killar, L. R. Gilde, K. M. Strohmaier, A. R. Meibohm, M. D. Miller, D. J. Hazuda, M. L. Nessly, M. J. DiNubile, R. D. Isaacs, B. Y. Nguyen, and H. Teppler. 2008. Raltegravir with optimized background therapy for resistant HIV-1 infection. N Engl J Med 359:339-54.

52. Underwood, M., B. Johns, A. Sato, T. Fujiwara, and W. Spreen. 2009. S/GSK1349572: a next generation integrase inhibitor with activity against integrase inhibitor-resistant clinical isolates from patients experiencing virologic failure while on raltegravir therapy. 5th IAS Conference on HIV Pathogenesis, Treatment and Prevention:Cape Town, South Africa, July 2009.

53. Van Baelen, K., V. Van Eygen, E. Rondelez, and L. J. Stuyver. 2008. Clade-specific HIV-1 integrase polymorphisms do not reduce raltegravir and elvitegravir phenotypic susceptibility. AIDS 22:1877-80.

54. Vingerhoets, J., H. Azijn, E. Fransen, I. De Baere, L. Smeulders, D. Jochmans, K. Andries, R. Pauwels, and M. P. de Bethune. 2005. TMC125 displays a high genetic barrier to the development of resistance: evidence from in vitro selection experiments. J Virol 79:12773-82.

55. Westby, M., C. Smith-Burchnell, J. Mori, M. Lewis, M. Mosley, M. Stockdale, P. Dorr, G. Ciaramella, and M. Perros. 2007. Reduced maximal inhibition in phenotypic susceptibility assays indicates that viral strains resistant to the CCR5 antagonist maraviroc utilize inhibitor-bound receptor for entry. J Virol 81:2359-71.

56. Xu, L., J. Anderson, B. Ferns, P. Cook, A. Wildfire, J. Workman, S. Graham, and E. Smit. 2008. Genetic diversity of integrase (IN) sequences in antiretroviral treatment-naive and treatment-experienced HIV type $2 \mathrm{pa}-$ tients. AIDS Res Hum Retroviruses 24:1003-7.

\section{Address for correspondence:}

François Clavel, M.D.

Inserm U941

Institut Universitaire d'Hématologie

Hôpital Saint-Louis

Paris

France

E-mail: francois.clavel@inserm.fr 